\title{
Effect Of Individual Characteristics On Career Development Through Continuing Management Education
}

\author{
Abida Ayub \\ Department of Management,University of Gujrat, (abida.ayub3@gmail.com) \\ Tooba \\ University of Gujrat ,Sub campus Rawalpindi,(tooba.israr1417@gmail.com) \\ Humera \\ University of Gujrat, Sub campus Rawalpindi, (nazhumera123@gmail.com) \\ Sadaf \\ Department of Business Administration PGCW, (Nazsadaf66@gmail.com) \\ Dil Awaiz \\ University of Gujrat, (dilawaiz04@gmail.com) \\ Amna \\ University of Gujrat.(amnaraja53@gmail.com)
}

\begin{abstract}
This study is based on determining the influence of individual characteristics on pursuing continuing management education for carrier development of employees. That being educated in certain area of technical expertise, and being managerially trained are two different perspectives and how the later one effects the personal and professional growth of an employee. The data is collected from potential employees in areas which require continuing management education programs. The data is collected in form of quantitative questionnaires expanding over the scope of this research. The results indicate that individual characteristics actually have strong impact on selection of appropriate CME program.
\end{abstract}

Keywords: Career Development, Management Education

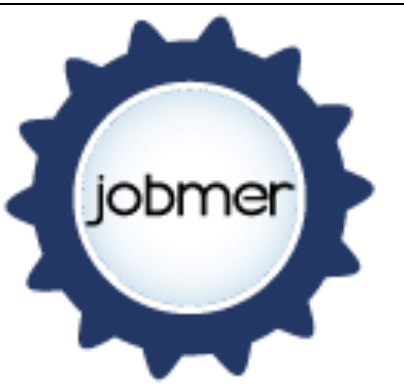

Journal of Business Management and Economic Research

Vol.2, Issue.4, 2018

pp.39-47

Doi: 10.29226/TR1001.2018.29 
Abida Ayub -Tooba - Humera - Sadaf - DilAwaiz - Amna, 2018, Vol.2, Issue.4, pp.39-47

\section{INTRODUCTION}

The knowledge is continuously expanding in the recent era, where people are doing continuous researches resulting in expansion of existing knowledge. The degrees the certificates matter a lot in the current corporate culture. So to cope up with these requirements of the recent era, and individual must decide that what would be his next step of survival. Whether he wants to survive the competition by gaining extra knowledge or he wants to stay at a stable stress-free platform in the organization and be most likely to lose his job over the competition.

Being extinct of an employee does not matter for the organization, but it highly affects the career development and overall morale of that individual. So to move forth in the steps of carrier developmental process and employee must acquire additional skills and capabilities through continuing management education. Sometimes a person is good at his technical expertise, but needs some management skills to make sure he manages efficiently and effectively. This specially happens when a person is having a highly technical educational background and he is handed over the responsibility of a manager in position in an organization so he is in need of education in the management field so he can plan, organize, lead and control the faculty and resources with maximum precision and accuracy possible.

Nowadays people are facing many difficulties regarding the carrier. They are in a position in an organization and they need to move forward in the hierarchy of authority. To exploit their strengths and suppress their weaknesses they are required to gain extra knowledge. Knowledge to make sure they are worth of their new position in the organization. Institutes are providing management education for the people who are currently enrolled as employees of some existing organizations. They are willing to provide flexibility to the people who can manage some hours from the tight work schedule.

Why is this need arising? Why are people needed to gain extra education? It is needed Because of the tough competition in the employee hiring and staffing. An individual has to acquire some competitive edge over the other pool of applicants arising for a vacant position in the company. They need that distinguishing factor for which they will be selected over others; they will be prioritized over others. A person is most of the times not satisfied from the current position in an organization he wants to go up and beyond his current power and expertise.

Being stuck in a single job position is stable but not healthy for carrier development. A person must learn to move forward and embrace the competition of his existence in an organization. A person's mental and cognitive abilities are not enough for him, so that he would be capable person for an organization. But his mental abilities for deciding the necessary requirements he would achieve to stay in that organization are relevant. He might not be thinking about having a promotion in the organization but he needs those skills to make sure he is managing the resources appropriately. There are numerous types of Management education programs provided for the employees but he must be wise to choose the specific area where he needs the know-how. Is it motivation, team building, management of resources? Or any other likes financial, marketing, logistics, productions and operations or customer satisfaction area? $\mathrm{He}$ must choose the area responsibly. There, he must be performing cost and benefit analysis of which one is better for him, that he must be enrolled in a diploma or a degree program as per requirement.

How the person selects whether he wants a CME program or not, or which type of CME program he will most likely select depend on his personal characteristics. What are his motives of having the CME program, and why is he managing the extra load of a job and an additional and sometimes not so necessary CME program. It will always be his personal benefit, along with partially shared organizational benefit. So, if he is willing to take the pressure and strain of 
handling more than routine tasks on his plate, then he must be enthusiastic enough to claim the benefits of being a better employee and thus, moving a step further in his carrier development. It is always difficult to come out of one's comfort zone, but once you try to do so, you will be happy to reap the rewards.

So in today's, a person must consider continuing management education whichever field of knowledge they operate in. being aware as a manager and utilizing the techniques and understanding the theories provided by management sciences is taking the existing knowledge a step forward in whatever area of interest a person is currently pursuing. Because organizations involve people to work with, to negotiate with, to compensate with, to conflict with, to cooperate with as well as the resources to handle, the inventories to keep up, the deadlines to meet. Management is required everywhere.

\section{LITERATURE REVIEW}

\section{Individual Characteristics}

Individual characteristics are those qualities which exist in human beings and which distinguish them from others. Every person have diverse characteristics which renders its personality and which helps him toward various features of human behavior including motivation, learning, performance and also career development (Robbins, 1996, pp. 109-111). Every individual have different type of behavior and he acts according to his own cognition, perception and shows behavior which he accepts for himself. Good personality traits are very significant for an effective manager even for every employee because it leads him to success. Good personality traits ultimately results in being very helpful for stage to stage career development. Individual characteristics can be identified through observation, interviews and surveys.

Individual characteristics also emphasize the individual to take the decisions related to occupation and in that professional decision outcome, individual desires eventual goal achievements. This stage also involves expectations from surrounding people and environment which is very important for job satisfaction (Eka Daryanto, 2014). According to (Patton \& McMahon, 2006) personality traits are resolute through individual characteristics which can be measured by certain description. It is necessary for an individual to attain his superior level job performance According to (Mushriha, Dra, \& Msi, 2013) individual characteristics keep changing and it can be learned at any time and any place. Individual behavior is also result of the life experience of person and this behavior can also be changed through learning. Learning process can change the behavior of individual. Individual characteristics play very important role in decision making which is very important to choose any occupation because right option can lead you to success. Success is also a motivation factor to doing something if there is no motivation of gaining something then the interest of employee will be less as compare to if he have some ambitions and also loyal to himself and also with the organization in which he is working. (Robbins, 1996) Defines that around there are four features of an individual as a worker in relative to work. Those four features are: biographical, capabilities, personality and last is learning. These fours are matter a lot in individual life either in his/her personal life or professional life. Age, gender also effect performance and these factors make his/her personality according to which he act and show his/her interest.

Individual characteristics have close link and important role to make his career through continuous management education which is also important in this era to compete with other and for survival because if they do not learn new skills and technology then there is less chance of their successful career. 
Abida Ayub -Tooba - Humera - Sadaf - DilAwaiz - Amna, 2018, Vol.2, Issue.4, pp.39-47

\section{Continuous Management Education}

World is changed and become a global village. Everyone have to compete if he has to survive in the present era. As now world became a global village so there are different cultures in different countries according to which they used their technologies so it is necessary to adopt these cultures according to the requirement of the organization, for this they must be trained employees and organizations must also give them relevant education for better result. (Gupta, Bhaskar, \& Singh, 2015). Continuous management education is important for employees for their career development and also for organizational development. For continuous management education it is necessary that employees should be aware of the benefits provided by CME and also motivated to continue their study for further steps. The adults or persons involved in practical fields when acquire education, they can use it more efficiently as compared to children gathering random knowledge because they know where to concentrate and where the knowledge is applicable. (UNESCO Institute of lifelong learning, 2010). For CME employees have an option for selection of the courses which are most relevant to their occupational requirement and through which their personal skills will also enhance along with other carrier development benefits.

In history, many studies have been done in which they discussed the importance of continuous management education. People (Kim \& Nancy, 1990) have studied and knew that CME is not only option but also an essential in corporate world to acquire promotions, good salaries and also for work satisfaction in present era. Other researches emphasized that Continuous management education (CME) is very helpful for employees because CME teaches them to keep discovering themselves. It gives them latest knowledge to deal with different types of hurdles and also resolve and overwhelmed every unusual situation. In fact it gives them strength and capacity to resolve issues before they actually occur and cause loss. (Gupta, Bhaskar, \& Singh, 2015) The researchers have discovered the importance of continuous management education for employees. They examined the impact of continuing professional education on the performance of employees and found the results. He also realized that performance of employees can lead to better result through continuous management education (CME) and can make further progress in their respective field. Continuous management education (CME) is not only important for advancement of their prospective field but also promote them into next rank also increase their knowledge, abilities, skills and by improving their learning skills and enhancing their personality. (Walker, Jeffes, Hart, Lord, \& Kinder, 2010)

Usually the organization's management support the choice of CME programs but most often, the individual selects the most suitable program in relevance to his own personality regardless of the organizational benefits, he prioritizes his personal benefits (Ofsted, 2010). The first and the most important element for an employee is salary income, income is very important for them and income determine their status in society and also shapes their lifestyles so through continuous management education (CME) they not only improve their personal and professional growth but also raise their income and which is also a very important motivation factor for employee obtained by getting more skills and knowledge through continuous management education (CME). (Walker, Jeffes, Hart, Lord, \& Kinder, 2010). No one can deny the importance of continuous management education (CME) for employees for their career development as individual characteristics are important for career development in the irrespective of the field in which they are working.

\section{Career Development}

Every individual have some plans for future. These plans can be for his professional growth or for personal growth. Both things are included in career development and both are important for 
individuals. In these days mostly organizations plan career development for employees. The basic purpose of this planning is the professional as well as personal growth of employees which leads them to their successful career and also beneficial for the organization. (Kim \& Nancy, 1990). It is also said that career development is a formal term which is used in business and also it focuses on continuously increasing the skills and abilities of employees. Through career development, employees improve their abilities and also become more motivated to perform their tasks in dynamic environment (Nawawi \& Hadari, 2000, p. 289). According to the results of another research, young employees are more motivated to beginning a career in the replacement because of high level of values they perceive as compare to old employees, because old employees have minimum level of motivation and also low interest for career development they do not want frequent variations and modifications in their work atmosphere. They also do not want to work in dynamic environment because generation $X$ usually comprises of Herzberg's Theory $X$ type employees so they do not like diversity and that's why career development is less in old employees (Campion, et al., 1994). According to (Dubrin \& Andrew, 1982, p. 197) the career development in the view point of the organization, is personal activity in which his/her colleagues help individual plan in future for the help of individuals and for the creativity in the organization to achieve maximum self-development. Many programs are offered for the development of employees and career development is essential staffing activity which helps employees to plan for future career in the organization where employees which have concerns about their career can advance their selves. (Handoko \& Hani, 2001, p. 123) said that the career development is a personal improvement which one does to achieve his/her career plan. It is personal activity to plan career achievement it can be professional growth and also can be personal growth. For career development motivation factor should be there in employees otherwise they do not make plans for career. For this purpose many organizations also aware their employees that how much career development is important for employees as well as for the organization. If employees are not conscious of their future plans they do not know in future which goal they would be supposed to achieve in the organization for professional growth. This results in the employees having low level of loyalty toward organization. That's why it is also important to spread awareness of career development to employees.

The decision of carrier development is based on three dimensions, first of all relationship between commitment and action, secondly, history and experience of the person deciding, and thirdly the dynamic linkages between networks involved (Langley, Mintzberg, Pitcher, Posada, \& SaintMacary, 1995). These decisions also involve the status quo bias that the individual would prefer the existing line of decisions made by him and thus he will act to stick with the old intentions. He may want to carry his social image within the organization or want to do the usual personality up-gradation decisions regarding his carrier. (Sameulson \& Zeckhauser, 1988 ) .

\section{THEORETICAL FRAMEWORK}

A summarized diagram of the research to be conducted is given below.
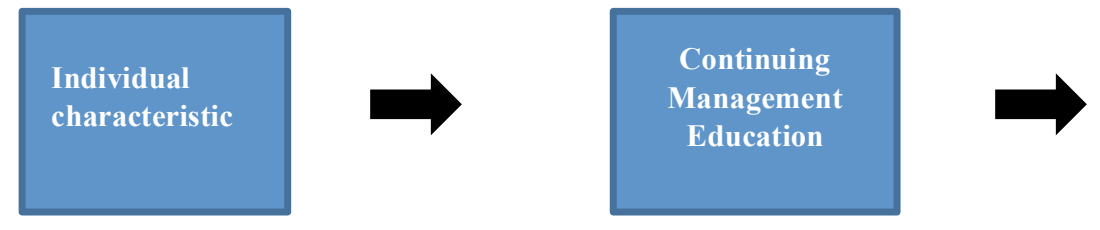

Career

Development 
Following are the suggested hypothesis

H1: individual characteristics is positively associated with continuing management education

H2: Continuing management education is positively associated with career development

H3: Continuing management education has positively mediated between individual characteristics and career development.

\section{METHODOLGY:}

In this study quantitative technique was used to explore the relationship between individual characteristics, continuing management education and career development.. Target population was selected as private sector of Rawalpindi and Islamabad. In present study data was collected through questionnaire. Non probability technique that is convenient sampling is used for data collection. There were 300 questionnaires out of which 256 respondents give their response. Male proportion was greater in the population as compared to females. There were $65.5 \%$ male and $34.5 \%$ females.

\section{Measure:}

Career development was measured using four questions developed by Noe, 1996; Zikic \& Klehe 2006.The questionnaire employed in the present study consists of questions that measure the individual characteristics taken from the Work-style Survey (Feuerstein et al., 2005).. The items were mainly on a four point scale (Never - At least three times per week).

According to descriptive statistics mean value and standard deviation value of individual characteristics measured at 2.62 and 0.843 respectively. Similarly mean and standard deviation value for career development is 2.72 and 0.940 respectively. And for CME mean value is 23.3 and 18.33 is its standard deviation value.

Table: 1 Correlation and Alpha reliability of individual characteristic, CME, and career development $(\mathrm{N}=256)$

\begin{tabular}{lllll}
\hline & & I & II & III \\
\hline I & Individual characteristic & .793 & & \\
II & CME & $.763^{* *}$ & .731 & \\
& & & & .599 \\
III & Career development & $.670^{* *}$ & $.762^{* *}$ & \\
\hline
\end{tabular}

${ }^{* *} \mathrm{p}<0.01$ level

The above table 1 shows that two variables individual characteristics and career development are significantly and positively correlated $(\mathrm{r}=.670, \mathrm{p}<.01)$. This proves that the first hypothesis is accepted as there is positive and significant relationship between these two variables. Similarly, above table shows that there is a positive and significant relationship between CME and career development $(\mathrm{r}=.734, \mathrm{p}<.01)$. 


\section{TESTING MEDIATION EFFECT:}

To give evidence of the mediation effect among all three variables four assumptions of Baron and Kenny (1898) has been used in this study. According to his first supposition independent variable have affect on the mediator. Second statement says that mediator variable in any study should affect the dependent variable of that study. According to his third assumption independent variable of a study should be related to dependent variable of that study. Last assumption of Baron and Kenny illustrates that if dependent and independent variable have no direct relationship between with one another, but the relationship exists because of mediator than there is a case of full mediation. And in partial mediation dependent and independent variable have both direct and indirect (through mediator) relationship with one another. Sobel test is used for testing the mediation of CME.

\begin{tabular}{lllll}
\hline Mediation Relationship & Hypothesis & $\begin{array}{l}\text { Sobel Test } \\
\text { Statistics }\end{array}$ & P Value & Result \\
\hline Individual & H6 & 10.13 & 0.00 & $\begin{array}{l}\text { Accepted } \\
\text { (Partial } \\
\text { mediation) }\end{array}$ \\
$\begin{array}{l}\text { Characteristics }=>\mathrm{CME}=> \\
\text { Career development }\end{array}$ & & & & \\
\hline
\end{tabular}

\section{DISCUSSION:}

Main aim of this study was to verify the effect of individual characteristics on the career development. This study finds out this relationship in the presence of a very important variable used as a mediator. Continuing management education was used as mediator in this relationship. Whenever CME is used in any organizational scenario it leads to the increase in the career development of employees in that working environment. This finally leads to increase the final output of employees that is employee performance. Objective of this study was to explore the mysterious black box that exists between the dependent and independent variable.

H1 of this study indicates the relationship of individual characteristic on continuing management education. Result supported the first hypothesis. Past researchers also prove this relationship has a strong and positive impact on performance and development of employees. $\mathrm{H} 2$ suggest that there is a positive effect of high continuing management education on career development. Result of this study proves the second hypothesis of this study

H3 indicates the mediating role of continuing management education between individual characteristic and career development. Results of this study prove that CME positively mediates the relationship between individual characteristics and career development.

\section{CONCLUSION}

Main aim of this study was to examine the factor that contributes in the relationship of individual characteristic and career development. It means the individual characteristics actually have a strong impact on carrier development through choice of appropriate CME programs. Because when an individual makes certain decisions regarding the CME program, his personality traits have strong influence over the decision. And the decision thus impacts his personal and professional growth. So, the hypotheses proposed in this research are presumably valid. . Individual characteristics play a vital role to achieve a successful career because if an 
individual have ability to achieve a specific goal and he knows it, then he will try to do better and he will try to get his goal through learning. Finally he will achieve his goal so in result of it he acquires better personality traits so individual can move on with better self. The most necessary elements which must be in individual for success in career development include job skills, demonstrative intelligence and also IQ level (Muchlas \& Makmuri, 2005). Individuals have always some capacity to learn more either it is related to any skills or behavior because learning process can occur any time and there are many chances to be acknowledged, to enhance your personality and he can also improve his career.

\section{THEORETICAL AND PRACTICAL IMPLICATIONS}

This study helps many researchers and organizations to enhance the performance of their employees by considering in relation with $\mathrm{CME}$ and individual characteristics. This study helps in various dimensions. First of all, the research covers the management section of knowledge involving employees "working" in an organization. And it emphasizes on the need of survival and moving forth in the existing system. Secondly, it is combined with the psychological aspects of personality and characteristics of an individual for analyzing unambiguous decision making traits in certain scenario. The scenario in this case is the continuing management education programs provided by various institutions. So these elements are not studied collectively together before.

This study adds benefit by explaining the effect of CME on employees' development in Pakistani working environment. Pakistani businessmen can enhance the performance of their employees by using bundles of practices along with CME. It shows a clear picture that organizations should use continuing management program for the betterment of their employees' career.

\section{LIMITATIONS AND FUTURE RESEARCH}

This study is enormous as it includes four variables and their relationship with one another but as all other studies this study also have some limitations in it. There was a problem of generliazability due to its sample size. Data collected in this study was self reported, further researchers can get rid of biasness by not collecting self reported data. This study is conducted in only one sector further researchers can take more sectors to enhance the accuracy of results. This study is cross sectional future searchers can check the results by conducting at longitudinal level.

\section{REFERENCES}

Campion, Michael, A., Cheraskin, Lisa, Stevens, \& Michael, J. (1994). Carrier-Related antecedentsand outcomes of Job Rotation. Academy of Management Journal Vol 37, 1518-1542.

Chaudhry, T. I., Naz, S., Naz, H., Kiani, D. S., \& Ashfaq, A. (2016). Effect of Individual Characteristics on Carrier Development through Continuing Management Education. 30.

Dubrin, \& Andrew, J. (1982). Personal and Human Resource Management. California: Kent Publishing Company.

Eka Daryanto. (2014). Individual characteristics and carrier development: a study on vocational school teachers, satisfaction in Indonesia. American Journal of Research Volume 2 , no. 8,698702.

Gupta, K. P., Bhaskar, P., \& Singh, S. (2015). Role of Continuing Management Education (CME) in Career Development (CD): A Study of BPO Industry in NOIDA. Research Gate, 57.

Handoko, T., \& Hani. (2001). Manajemen Personalia dan Sumber daya Manusia. Yogyakarta: BPFE-Yogyakarta. 
Kim, \& Nancy, J. (1990). "Continuing Education Is No Longer an Option.". Puget Sound Business Journal, 27.

Langley, A., Mintzberg, H., Pitcher, P., Posada, E., \& SaintMacary, J. (1995). Opening up Decision Making: The view from the Black Stool. Organization Science Vol 6.

Muchlas, \& Makmuri. (2005). Perilaku Organisasi. Yogyakarta: Gadjah Mada University Press, 82.

Mushriha, H. J., Dra, E., \& Msi. (2013). The impact of Individual Characteristics and organizational culture on performance and carrier development of employees Case studies Five Star hotel in Surbaya, Indonesia. IQSR Journal of Business and Management Vol 14, Issue 3.

Nawawi, \& Hadari. (2000). Manajemen Sumber Daya Manusia: Untuk Bisnis Yang Kompetitif. Yogyakarta: Gajah Mada University Press.

Ofsted. (2010, August 12). Good professional development in schools. How does leadership contribute? HMI 080254, 54. Retrieved from http://www.ofsted.gov.uk/Ofstedhome/Publications-and-research/Browseall-by/Documents-by-type/Thematic-reports/Goodprofessional-developmentin-schools

Patton, W., \& McMahon, M. (2006). Carrier Development and systems Theory: Connecting Theory and Practice. Sense Publisers.

Robbins, S. (1996). Organization Theory. Third Edition New York: Prentice-Hall, Inc.

Sameulson, W., \& Zeckhauser, R. (1988 ). Status quo Bias in Decision Making. Journal of Risk and Uncertainity Vol 1 Issue 1, 7-59.

UNESCO Institute of lifelong learning. (2010). Global report on adult learning and education. Retrieved

from http://uil.unesco.org/fileadmin/keydocuments/AdultEducation/en/GRALE_en.pdf

Walker, Jeffes, Hart, Lord, \& Kinder. (2010). Making the links between teachers' professional standards, induction, performance management and continuing professional education. Department for Education, $153 . \quad$ Retrieved from https://www.gov.uk/government/uploads/system/uploads/attachment_data/file/182227/D FERR075.pdf 